\title{
Correction to: Surveillance of Low-Grade Appendiceal Mucinous Neoplasms With Peritoneal Metastases After Cytoreductive Surgery and Hyperthermic Intraperitoneal Chemotherapy: Are 5 Years Enough? A Multisite Experience
}

Daniel Solomon, $\mathrm{MD}^{1}$, Eliahu Bekhor, $\mathrm{MD}^{1}$, Natasha Leigh, $\mathrm{MD}^{1}$, Yash M. Maniar, BA ${ }^{1}$, Linsay Totin, $\mathbf{B S}^{\mathbf{2}}$, Margaret Hofstedt, BS ${ }^{\mathbf{1}}$, Samantha N. Aycart, $\mathbf{P A}^{\mathbf{1}}$, Jacquelyn Carr, $\mathbf{M D}^{\mathbf{1}}$, Samuel Ballentine, $\mathrm{MD}^{3}$, Deepa R. Magge, $\mathrm{MD}^{1}$, Benjamin J. Golas, $\mathrm{MD}^{1}$, Reetesh K. Pai, $\mathrm{MD}^{4}$, Alexandros D. Polydorides, MD, $\mathbf{P h D}^{3}$, David L. Bartlett, $\mathbf{M D}^{2}$, Daniel M. Labow, $\mathrm{MD}^{\mathbf{1}}$, Haroon A. Choudry, $\mathrm{MD}^{2}$, and Umut Sarpel, $\mathrm{MD}^{1}$

${ }^{1}$ Division of Surgical Oncology, Department of Surgery, Icahn School of Medicine at Mount Sinai, New York, NY;

${ }^{2}$ Surgical Oncology, University of Pittsburgh Medical Center, Pittsburgh, PA; ${ }^{3}$ Department of Pathology, Icahn School of Medicine at Mount Sinai, New York, NY; ${ }^{4}$ Department of Pathology, University of Pittsburgh Medical Center, Pittsburgh, PA

\section{CORRECTION TO: ANN SURG ONCOL}

HTTPS://DOI.ORG/10.1245/S10434-019-07678-0

In the original version of the article, Margaret Hofstedt's last name was misspelled. It is correct as shown here. The original article has been corrected.

The original article can be found online at https://doi.org/10.1245/ s10434-019-07678-0.

(C) Society of Surgical Oncology 2019

Published Online: 19 August 2019

U. Sarpel, MD

e-mail: umut.sarpel@mountsinai.org 